\title{
Symptomatic vergence disorders in junior high school children in Ghana
}

\begin{tabular}{|c|c|}
\hline \multicolumn{2}{|c|}{$\begin{array}{l}\text { Authors: } \\
\text { Charles Darko-Takyi }^{1} \\
\text { Naimah E. Khan }{ }^{2} \\
\text { Urvashni Nirghini }\end{array}$} \\
\hline \multicolumn{2}{|c|}{$\begin{array}{l}\text { Affiliations: } \\
{ }^{1} \text { Department of Optometry, } \\
\text { University of Cape Coast, } \\
\text { Ghana }\end{array}$} \\
\hline \multicolumn{2}{|c|}{$\begin{array}{l}{ }^{2} \text { Discipline of Optometry, } \\
\text { University of KwaZulu-Natal, } \\
\text { South Africa }\end{array}$} \\
\hline \multicolumn{2}{|c|}{$\begin{array}{l}\text { Research Project no.: } \\
\text { BE411/13 } \\
\text { GHS-ERC } 86 / 04 / 14\end{array}$} \\
\hline \multicolumn{2}{|c|}{$\begin{array}{l}\text { Corresponding author: } \\
\text { Charles Darko-Takyi, } \\
\text { chadarko@yahoo.com }\end{array}$} \\
\hline \multicolumn{2}{|c|}{$\begin{array}{l}\text { Dates: } \\
\text { Received: } 29 \text { Oct. } 2015 \\
\text { Accepted: } 07 \text { Apr. } 2016 \\
\text { Published: } 26 \text { July } 2016\end{array}$} \\
\hline \multicolumn{2}{|c|}{$\begin{array}{l}\text { How to cite this article: } \\
\text { Darko-Takyi C, Khan NE, } \\
\text { Nirghini U. Symptomatic } \\
\text { vergence disorders in junior } \\
\text { high school children in } \\
\text { Ghana. Afr Vision Eye Health. } \\
\text { 2016;75(1), a333. http:// } \\
\text { dx.doi.org/10.4102/aveh. } \\
\text { v75i1.333 }\end{array}$} \\
\hline \multicolumn{2}{|c|}{$\begin{array}{l}\text { Copyright: } \\
\text { (C) 2016. The Author(s). } \\
\text { Licensee: AOSIS. This work } \\
\text { is licensed under the } \\
\text { Creative Commons } \\
\text { Attribution License. }\end{array}$} \\
\hline \multicolumn{2}{|l|}{ Read online: } \\
\hline 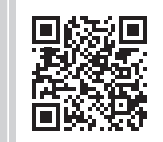 & $\begin{array}{l}\text { Scan this QR } \\
\text { code with your } \\
\text { smart phone or } \\
\text { mobile device } \\
\text { to read online. }\end{array}$ \\
\hline
\end{tabular}

Background: Optometrists in Ghana are hampered in performing comprehensive binocular vision assessments, because of the lack of appropriate instruments leading to a paucity of data on vergence disorders and their association with asthenopia among Ghanaian school children.

Aim: To establish the prevalence of symptomatic vergence disorders among junior high school (JHS) children in Cape Coast Metropolis, Ghana, in their habitual (vision) states and investigate if there were any associations between these disorders and specific asthenopic symptoms.

Methods: A prospective cross-sectional school-based study using a multistage sample of 627 participants aged 12-17 years from JHSs in Cape Coast Metropolis. Participants completed a reliable asthenopic symptoms questionnaire and 220 participants who expressed two or more severe or very severe symptoms were selected for comprehensive binocular vision assessment in their habitual vision state.

Results: The prevalence of symptomatic vergence disorders among JHS children in Cape Coast Metropolis was $14.8 \%$. For specific symptomatic vergence disorders, the prevalence was: $1.4 \%$ basic esophoria, $1.4 \%$ basic exophoria, $8.6 \%$ convergence insufficiency, $1.8 \%$ convergence excess, $0.8 \%$ fusional vergence dysfunctions and $0.8 \%$ divergence excess. No participant had symptomatic divergence insufficiency. The study revealed significant associations between some specific symptomatic vergence disorders and specific asthenopic symptoms even though all of these asthenopic symptoms overlapped in other vergence disorders.

Conclusion: Presenting complaints of specific asthenopic symptoms does not differentiate between specific types of vergence disorders. A comprehensive binocular vision assessment is vital in the diagnosis and management of these disorders to relieve asthenopia.

\section{Introduction}

Studies by Scheiman et al. on a clinical paediatric population ${ }^{1}$ and Lara et al. on a clinic population aged 10-35 years ${ }^{2}$ reported that the most common vision disorder after ametropia was binocular vision disorders. In comparison with certain ocular diseases also, binocular vision disorders are regularly diagnosed. ${ }^{3}$ Vergence disorders (binocular vision disorders ${ }^{4}$ functionally classified descriptively by clinical signs as convergence insufficiency, convergence excess, divergence insufficiency, divergence excess, basic exophoria, basic esophoria and fusional vergence dysfunctions ${ }^{5}$ ) have considerable impact on learning, social life and academic achievement in general $^{6}$ and thus can have significant negative effects on quality of life. ${ }^{3}$

The visual demands needed to complete school work usually involves substantial near reading and the use of the vergence system. ${ }^{7}$ As children progress from one level to the next in school, they encounter common typeface that are smaller, words and letters that are closer together, and reading passages with increasing length and difficulties. In addition, with the increased use of screen-based devices by school children, their near visual demands are also increased. ${ }^{8}$ One author reports that there is a high prevalence of accommodative and non-strabismic binocular vision disorders in school-going children compared with infants to pre-schoolers. ${ }^{9}$ Vergence disorders, such as convergence insufficiency, do become a significant clinical problem most especially when a patient reaches the teenage years. ${ }^{10}$ The characteristic asthenopic symptoms - experienced in the habitual state - are then exacerbated through increased school work and prolonged periods of reading. ${ }^{9}$ Patients most often encountered include high school students, because of the higher demands placed on their near vision system from extended periods of academic work. ${ }^{10}$

Few studies ${ }^{11,12,13}$ have been conducted in Ghana in the area of binocular vision; however, these studies also did not comprehensively investigate for vergence disorders. In a study of 
72 individuals who had their binocular function assessed, ${ }^{11}$ heterotropia and heterophoria were present in 15 (20.8\%) at near fixation and $8(11.1 \%)$ at distant fixation. Eighteen (25.0\%) of the participants examined had convergence insufficiency. In a study by Ovenseri-Ogbomo et al. in the central region of Ghana, the use of the cover test revealed that $20.6 \%$ of deaf and hearing-impaired children had various forms of heterophorias or heterotropias. ${ }^{12}$ The proportion of participants with convergence insufficiency was estimated at $12.1 \%$ using only receded near point of convergence (NPC) as the diagnostic criterion. None of the studies above emphasised investigating specifically for the different types of vergence disorders, and all used only one clinical sign as the diagnostic criterion. Out of 86 eye clinics sampled in a study in two major cities in Ghana, it was revealed that $63(73.3 \%)$ managed binocular vision anomalies. ${ }^{13}$ This study mentioned that possibly there could be a lack of provision of efficient binocular vision services because most clinics lacked binocular visionrelated instruments for proper and comprehensive assessment and management.

No information is available on the prevalence of vergence disorders among junior high school (JHS) children, and associations between possible variables like asthenopia that affect these conditions. The absence of this information means that appropriate services cannot be provided for this age group, their school work is likely to suffer, as is their long-term scholastic and work opportunities, and ultimately their quality of life. This study aimed to establish the prevalence of symptomatic vergence disorders (SVDs) among JHS children (in their habitual state as regard to vision correction and use thereof) in Cape Coast Metropolis, Ghana, and determine whether there were any associations between the asthenopic symptoms and SVDs.

\section{Research methods and design}

A prospective cross-sectional school-based study was conducted in JHS children in the Cape Coast Metropolis. The study population involved 9153 JHS students. ${ }^{14}$ Only students within the age range of 12-17 years were included in the study. Students with any one of the following were excluded from the study: visual acuity worse than 0.2 on LogMAR chart, strabismus, blindness, pathological conditions both external and internal, eye infections and ocular media opacities. Minimum sample size was not expected to be less than 317 to make the study representative of the population concerned. However, the study sample was increased to give it greater statistical power. A multistage sampling strategy was used. Seventy-three (73) JHSs in the metropolis were grouped into six clusters and simple random sampling was then used to select two schools from each of the six clusters. Fifty-three (53) students were randomly selected from each of the 12 selected schools. In all, 636 students were sampled and 9 were excluded ( 1 with strabismus, 2 with ocular media opacities and 6 with visual acuity worse than $0.2 \log M A R) ;$ hence 627 JHS students participated in study.

\section{Data collection}

The main outcome measures for SVD was the presence of two or more ${ }^{15}$ severe or very severe symptoms of asthenopia and detection of more than $80 \%$ of the clinical signs of specific vergence disorders during binocular testing. A reliable (see below) asthenopic symptom questionnaire and examination form which comprised optometric clinically accepted routine test procedures were used to collect data. The questionnaire (Figure 1) consisted of 20 symptoms associated with the use of the eye for distance or near vision and symptom severity were measured on a grading scale $(0$ - never, 1 - mild, 2 - moderate, 3 - severe, 4 - very severe). Participatory pretests were conducted in which 10 Ghanaian JHS student responders' understanding of the questions were determined and their comments factored into modifications of the questions. Undeclared pretesting continued where the questionnaire was administered again to 42 different JHS respondents outside the sample frame and reliability was checked using Cronbach's alpha test. The asthenopic symptom questionnaire for the study appeared to have good internal consistency with $\alpha=$ 0.866. All items appeared to be worthy of retention: the greatest increase in alpha would arise from deleting item 10 (double vision at far), but removal of this item would increase alpha only by 0.02 . This questionnaire was administered to all 627 participants, and those 220 participants who reported two or more $^{15}$ severe or very severe asthenopic symptoms were considered symptomatic and were selected for the full binocular vision examination.

Clinical examinations were performed by the first author and three doctors of Optometry from the Optometry Department of the University of Cape Coast, Ghana. These examiners were taken through training on the protocol and test procedures for the study to promote consistency in instructions, measurements, results and recordings. All binocular vision testing were done over participant's spectacle prescriptions if they used one or with no prescription if they did not use one. The manual lensmeter (Briot LM-25) was used to check and confirm spectacle prescriptions and these prescriptions were set in the manual phoropter (Topcon VT-10) before binocular vision testing was done for such participants. The binocular vision examination procedures included positive relative accommodation (PRA) and negative relative accommodation (NRA), NPC using a vertical row of 20/30 Snellen letters as target, habitual lateral phorias at distant and near using the von Graefe technique, gradient $\mathrm{AC} / \mathrm{A}$ ratio and positive and negative fusional vergence measurement at distant and near using Risley prisms from a manual phoropter (Topcon VT-10). The results of phoria tests, fusional vergence measurements, relative accommodation and $\mathrm{AC} / \mathrm{A}$ ratio were compared with normative values from the 'expected values for accommodative and vergence testing', ${ }^{4}$ and NPC results were compared with a cut-off normative break of $5 \mathrm{~cm}$ and recovery of $7 \mathrm{~cm} .{ }^{16}$ More than $80 \%$ of the clinical diagnostic signs - for each of the specific vergence disorders - which deviated from the normal ranges were grouped together to diagnose vergence disorders using criteria by Scheiman and Wick. ${ }^{5}$ 


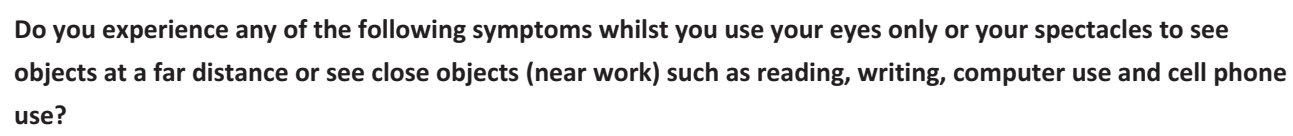

If 'YES', indicate by ticking ( $\mathrm{V}$ ) appropriately how severe is/are the symptom(s).

\begin{tabular}{|c|c|c|c|c|c|}
\hline \multirow[t]{3}{*}{ Symptom } & \multirow[t]{2}{*}{ Never } & \multicolumn{4}{|c|}{ Yes } \\
\hline & & Mild & Moderate & Severe & Very severe \\
\hline & 0 & 1 & 2 & 3 & 4 \\
\hline \multicolumn{6}{|c|}{ Headaches associated with near work } \\
\hline \multicolumn{6}{|l|}{ Headaches associated with far vision } \\
\hline \multicolumn{6}{|c|}{ Eye fatigue associated with near work } \\
\hline \multicolumn{6}{|c|}{ Eye fatigue associated with far vision } \\
\hline \multicolumn{6}{|l|}{ Blurred vision at near } \\
\hline \multicolumn{6}{|l|}{ Blurred vision at far } \\
\hline \multicolumn{6}{|c|}{ Watery eyes (tearing) with near work } \\
\hline \multicolumn{6}{|l|}{ Watery eyes (tearing) with far vision } \\
\hline \multicolumn{6}{|c|}{ Double vision associated with near work } \\
\hline \multicolumn{6}{|c|}{ Double vision associated with far vision } \\
\hline \multicolumn{6}{|l|}{ Flashes of light } \\
\hline \multicolumn{6}{|l|}{ Eyestrain with near work } \\
\hline \multicolumn{6}{|l|}{ Eyestrain with far vision } \\
\hline \multicolumn{6}{|l|}{ Redness around eye } \\
\hline \multicolumn{6}{|l|}{ Eye pain with near work } \\
\hline \multicolumn{6}{|l|}{ Eye pain with far vision } \\
\hline \multicolumn{6}{|c|}{ Difficulty tracking objects during reading or near work } \\
\hline \multicolumn{6}{|c|}{ Difficulty tracking objects during far vision } \\
\hline \multicolumn{6}{|l|}{ Burning sensation with near work } \\
\hline Burning sensation with far vision & & & & & \\
\hline
\end{tabular}

FIGURE 1: Questionnaire on asthenopic symptoms.

\section{Data analysis}

The data collected were analysed using IBM SPSS Statistics (version 21). Descriptive statistics such as frequencies, means, standard deviations and ranges were used to analyse all the quantitative data. Distributions of variables were presented in text, tables and bar charts. Estimates of prevalence were presented in proportions with their corresponding 95\% confidence intervals. Independent sample $t$-tests were used to test for significant differences in age between genders. Pearson's chi-square tests were used to investigate possible associations between certain parameters and outcome variables. Multivariate binary logistic regression were also used to test for significant associations. A $p$-value of less than or equal to 0.05 was considered statistically significant.

\section{Ethical considerations}

The study was approved by the Biomedical Research Ethics Committee of the University of KwaZulu-Natal and by the Ghana Health Service Ethical Review Committee and the study conformed to the Declaration of Helsinki regarding research with human subjects. Institutional permission was sought and approved by the Cape Coast Metro Education Authority in Ghana, and also head teachers of the various JHSs in Cape Coast. JHS students agreed to participate and parents or guardians of participants provided signed informed consent. Information sheets and consent forms were written in English and in participant's native languages (Twi and Fante) and were approved by the Department of Ghanaian languages of the University of Cape Coast.

\section{Results}

The total study population included 627 participants of which $47.2 \%$ were males and $52.8 \%$ were females, with mean age of $14.05 \pm 1.49$ years. There was no significant difference in age between male and female participants $(t=0.982$, $p=0.16$ ). Of the 627 participants, 220 (mean aged $14.35 \pm 1.54$ years), which included $82(37.3 \%)$ males and $138(62.7 \%)$ females, reported not less than two severe or very severe symptoms of asthenopia and were selected for binocular vision examination. Of the 220 participants, 28 (12.7\%) used 
spectacles - 2 for near work, 15 for far vision, 8 for both near and far work and 3 were not specified.

The prevalence of SVDs in the JHS students in Cape Coast Metropolis $(n=627)$ was $14.8 \%(95 \%$ CI $12.26 \%-17.83 \%)$. Among only JHS participants with two or more severe or very severe asthenopic symptoms $(n=220)$, the frequency of SVD was $42.3 \%$ (95\% CI 35.93\% - 48.88\%). For the specific SVDs, the prevalence of convergence insufficiency was $8.6 \%$ (95\% CI 6.66\% - 11.07\%) among JHS participants and 24.5\% (95\% CI $19.33 \%-30.64 \%)$ among only JHS participants with severe or very severe asthenopic symptoms (Table 1); no participant was diagnosed with divergence insufficiency. A proportion of $36.6 \%(95 \%$ CI $26.98 \%-47.39 \%)$ of males and $45.7 \%$ (95\% CI $37.57 \%-53.97 \%)$ of females were diagnosed with SVDs, respectively. Of the participants who habitually used spectacles $(n=28), 35.7 \%$ (95\% CI 20.71-54.17) were diagnosed with SVDs. The symptom of headaches associated with near work was most prevalent (69.9\%) among participants with SVDs, and eyestrain with far work (23.7\%) was the least prevalent (Figure 2). Convergence insufficiency was highly distributed among the different asthenopic symptoms compared with the other specific SVDs (Figure 3).

There was no significant association between SVD and other variables like gender $\left(X^{2}=1.73, p=0.19\right)$ and spectacle wear $\left(X^{2}=0.57, p=0.45\right)$ respectively. In a univariate analysis, there was a significant association between SVDs and specific asthenopic symptoms, namely headaches associated with near work $\left(X^{2}=4.45, p=0.04\right)$, eyestrain with near work $\left(X^{2}=4.77\right.$, $p=0.03)$ and redness around the eye $\left(X^{2}=5.54, p=0.02\right)$. Participants with eyestrain with near work had greater odds of having SVDs (OR = 0.46, 95\% CI 0.23-0.90; $p=0.02)$ compared with other symptoms; participants with symptom of redness around the eye had greater odds of having SVDs (OR $=0.50$, 95\% CI 0.29-0.89; $p=0.02$ ) compared with other symptoms. Univariate analysis revealed some significant associations between some specific SVDs and some specific asthenopic symptoms (Tables 3 and 4). Participants with convergence insufficiency had greater odds of experiencing eye pain with near work $(\mathrm{OR}=0.45,95 \% \mathrm{CI} 0.22-0.92 ; p=0.03)$ and redness around the eye $(\mathrm{OR}=0.49,95 \% \mathrm{CI} 0.26-0.94 ; p=0.03)$ compared with other specific SVDs. Participants with fusional vergence dysfunctions had greater odds of experiencing eyestrain associated with near work (OR $=0.13,95 \%$ CI $0.02-0.82$; $p=0.03$ ) compared with other specific SVDs.

\section{Discussion}

This study is comparable to a study by Richman and Laudon ${ }^{17}$ who also conducted binocular testing in participant's habitual vision states in order to simulate the usual conditions under which participants functioned. With this strategy, the study sought to ascertain if there was an association between these asthenopic symptoms and the vergence disorders.

TABLE 1: Prevalence of specific symptomatic vergence disorders among Ghanaian junior high school students.

\begin{tabular}{|c|c|c|c|c|c|}
\hline \multirow[t]{2}{*}{ Symptomatic vergence disorder } & \multirow[t]{2}{*}{ Frequency } & \multicolumn{2}{|c|}{ Asthenopic participants $(n=220)$} & \multicolumn{2}{|c|}{ JHS participants $(n=627)$} \\
\hline & & $\%$ & Within $95 \% \mathrm{Cl}$ & $\%$ & Within $95 \% \mathrm{Cl}$ \\
\hline Basic esophoria & 9 & 4.1 & $2.17-7.59$ & 1.4 & $0.76-2.71$ \\
\hline Basic exophoria & 9 & 4.1 & $2.17-7.59$ & 1.4 & $0.76-2.71$ \\
\hline Convergence insufficiency & 54 & 24.5 & $19.33-30.64$ & 8.6 & $6.66-11.07$ \\
\hline Convergence excess & 11 & 5.0 & $2.81-8.73$ & 1.8 & $0.98-3.11$ \\
\hline Fusional vergence dysfunction & 5 & 2.3 & $0.97-5.21$ & 0.8 & $0.34-1.85$ \\
\hline Divergence excess & 5 & 2.3 & $0.97-5.21$ & 0.8 & $0.34-1.85$ \\
\hline
\end{tabular}

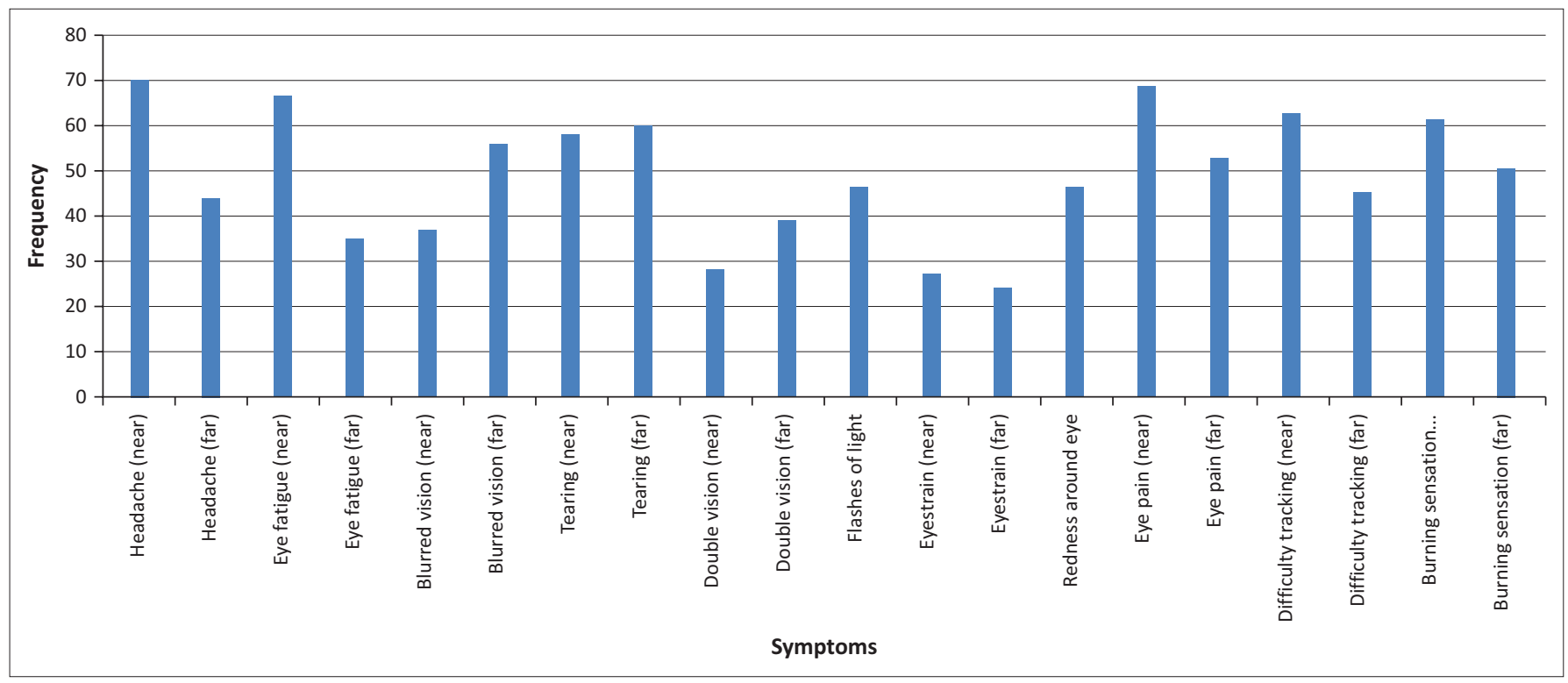

FIGURE 2: Distribution of asthenopic symptoms among junior high school participants with symptomatic vergence disorders. 


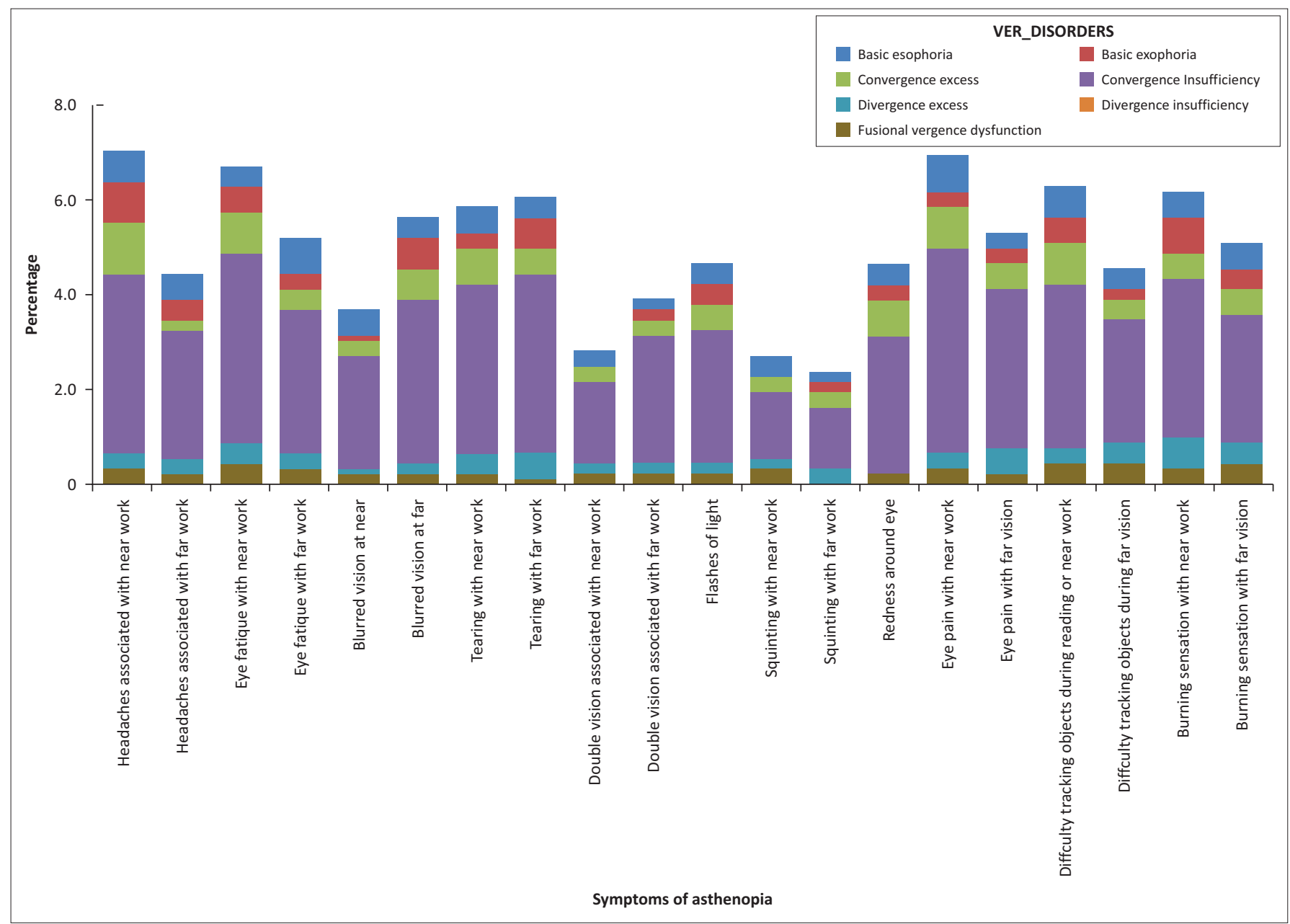

FIGURE 3: Distribution of vergence disorders among specific asthenopic symptoms.

TABLE 2: Association between specific symptomatic vergence disorders and asthenopia in univariate analysis.

\begin{tabular}{|c|c|c|c|c|c|c|}
\hline \multirow[t]{2}{*}{ Symptoms } & \multicolumn{2}{|c|}{ Basic esophoria } & \multicolumn{2}{|c|}{ Basic exophoria } & \multicolumn{2}{|c|}{ Convergence insufficiency } \\
\hline & $X^{2}$ & $P$ & $X^{2}$ & $p$ & $X^{2}$ & $p$ \\
\hline Headaches associated with near work & 0.09 & 0.76 & 2.91 & 0.09 & 0.27 & 0.60 \\
\hline Headaches associated with far vision & 0.78 & 0.38 & 0.04 & 0.85 & 0.72 & 0.40 \\
\hline Eye fatigue associated with near work & 0.89 & 0.35 & 0.06 & 0.80 & 2.39 & 0.12 \\
\hline Eye fatigue associated with far work & 3.95 & 0.05 & 0.56 & 0.46 & 1.18 & 0.28 \\
\hline Blurred vision at near & 2.22 & 0.14 & 1.99 & 0.16 & 2.09 & 0.15 \\
\hline Blurred vision at far & 0.08 & 0.78 & 1.16 & 0.28 & 2.96 & 0.09 \\
\hline Watery eye (tearing) with near work & 0.00 & 0.98 & 1.94 & 0.16 & 0.79 & 0.38 \\
\hline Watery eye (tearing) with far vision & 0.29 & 0.59 & 0.69 & 0.41 & 3.89 & 0.05 \\
\hline Double vision associated with near work & 0.31 & 0.58 & 3.20 & 0.07 & 0.66 & 0.42 \\
\hline Double vision associated with far vision & 0.72 & 0.40 & 0.72 & 0.40 & 3.68 & 0.06 \\
\hline Flashes of light & 0.77 & 0.78 & 0.08 & 0.78 & 1.98 & 0.16 \\
\hline Eyestrain with near work & 3.50 & 0.06 & 2.35 & 0.13 & 0.74 & 0.39 \\
\hline Eye strain with far vision & 0.10 & 0.75 & 0.10 & 0.75 & 0.77 & 0.38 \\
\hline Redness around eye & 0.21 & 0.65 & 0.06 & 0.80 & 4.96 & 0.03 \\
\hline Eye pain with near work & 1.07 & 0.30 & 3.11 & 0.08 & 4.88 & 0.03 \\
\hline Eye pain with far vision & 1.28 & 0.26 & 1.28 & 0.26 & 0.90 & 0.34 \\
\hline Difficulty tracking objects during near work & 0.34 & 0.56 & 0.01 & 0.92 & 0.12 & 0.73 \\
\hline Difficulty tracking objects during far vision & 0.08 & 0.78 & 1.24 & 0.27 & 0.59 & 0.44 \\
\hline Burning sensation with near work & 0.00 & 0.97 & 1.97 & 0.16 & 1.08 & 0.30 \\
\hline Burning sensation with far vision & 0.42 & 0.52 & 0.00 & 0.97 & 0.05 & 0.83 \\
\hline
\end{tabular}

Richman and Laudon, ${ }^{17}$ however, used a tertiary student population compared with the JHS population in the present study. All other studies reviewed ${ }^{2,18,19,20,21}$ apart from differences in study design, methodology and population ${ }^{22}$ evaluated for vergence disorders over best-corrected refraction results, thus the difficulty in comparing the present study with the other studies. Two studies ${ }^{18,21}$, which used similar age populations and study design, performed 
TABLE 3: Association between specific symptomatic vergence disorders and asthenopia in univariate analysis.

\begin{tabular}{|c|c|c|c|c|c|c|}
\hline \multirow[t]{2}{*}{ Symptoms } & \multicolumn{2}{|c|}{ Convergence excess } & \multicolumn{2}{|c|}{ Fusional vergence dysfunction } & \multicolumn{2}{|c|}{ Divergence excess } \\
\hline & $X^{2}$ & $p$ & $X^{2}$ & $p$ & $X^{2}$ & $p$ \\
\hline Headaches associated with near work & 4.15 & 0.04 & 0.01 & 0.93 & 0.007 & 0.93 \\
\hline Headaches associated with far vision & 2.57 & 0.11 & 0.004 & 0.95 & 0.73 & 0.39 \\
\hline Eye fatigue associated with near work & 0.84 & 0.36 & 0.89 & 0.35 & 0.89 & 0.35 \\
\hline Eye fatigue associated with far work & 0.39 & 0.54 & 0.44 & 0.51 & 0.44 & 0.51 \\
\hline Blurred vision at near & 0.16 & 0.69 & 0.12 & 0.73 & 0.38 & 0.54 \\
\hline Blurred vision at far & 0.14 & 0.71 & 0.17 & 0.68 & 0.17 & 0.68 \\
\hline Watery eye (tearing) with near work & 0.28 & 0.60 & 0.53 & 0.47 & 1.20 & 0.27 \\
\hline Watery eye (tearing) with far vision & 0.28 & 0.60 & 2.26 & 0.13 & 4.50 & 0.03 \\
\hline Double vision associated with near work & 0.02 & 0.89 & 0.57 & 0.45 & 0.57 & 0.45 \\
\hline Double vision associated with far vision & 0.34 & 0.56 & 0.05 & 0.83 & 0.05 & 0.83 \\
\hline Flashes of light & 0.14 & 0.71 & 0.85 & 0.36 & 0.85 & 0.36 \\
\hline Eyestrain with near work & 0.38 & 0.54 & 5.12 & 0.02 & 1.28 & 0.26 \\
\hline Eye strain with far vision & 0.00 & 0.97 & 1.88 & 0.17 & 2.87 & 0.09 \\
\hline Eye pain with near work & 0.63 & 0.43 & 0.004 & 0.95 & 0.004 & 0.95 \\
\hline Eye pain with far vision & 0.19 & 0.67 & 0.29 & 0.59 & 4.76 & 0.03 \\
\hline Difficulty tracking objects during near work & 1.13 & 0.29 & 1.08 & 0.30 & 0.02 & 0.90 \\
\hline Difficulty tracking objects during far vision & 0.06 & 0.80 & 3.41 & 0.07 & 3.41 & 0.07 \\
\hline Burning sensation with near work & 0.43 & 0.51 & 0.05 & 0.82 & 1.29 & 0.26 \\
\hline Burning sensation with far vision & 0.00 & 0.98 & 2.53 & 0.11 & 2.53 & 0.11 \\
\hline
\end{tabular}

binocular vision assessment over best-corrected refractive error results. 'Appropriate spectacle lens correction of any existing refractive error is the first consideration in treating persons with vergence anomalies'. ${ }^{4}$ Refraction however was not the focus of this study because there is a preponderance of data on refractive errors on children in Ghana. Even though some of the participants in their habitual state wore spectacles, they complained of severe or very severe asthenopic symptoms. The study sought to determine if the cause of asthenopia among participants who already wore spectacles was because of an unmanaged vergence disorder.

The detection and proper diagnosis of binocular vision dysfunctions necessitated a comprehensive battery of vergence and accommodative tests and a systemic method for the analysis of test results. These specific vergence tests and methods of

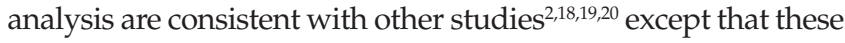
studies conducted the tests over routine refractive correction. In contrast to such studies, which utilised a lesser number of diagnostic signs, ${ }^{18,19,20}$ this study used more than $80 \%$ of all the clinical signs of specific vergence disorders. It is seldom that all the components of a diagnosis are present within any single patient. ${ }^{3}$ More diagnostic signs were adopted in our study since the prevalence value can be over-exaggerated with a lesser number of diagnostic signs and without best refractive correction. According to some studies, ${ }^{2,19}$ the prevalence values tend to reduce as the number of diagnostic signs increase. One study $^{2}$ used a similar number of diagnostic criteria, however, in contrast to the present study, the age range was completely different and the study design was clinic based. Consistent with other studies ${ }^{2,18,19}$ only participants with abnormal signs and symptoms were considered to have vergence disorders, thus the use of the terminology SVD in this present study.

Most of the studies reviewed were conducted only on symptomatic patients. ${ }^{2,18,19,20}$ It is however difficult to compare the general results of this present study to those other studies since the entire population of JHS students in our study included symptomatic and asymptomatic participants. Prevalence figures among only participants with symptoms (220) who were tested for signs of vergence disorders were compared with these other related studies. Dwyer ${ }^{18}$ determined a higher prevalence of vergence disorders (42.3\%) compared to the prevalence among symptomatic participants in our study. This difference in results apart from differences in study methodology may be attributed to the smaller sample (144) used in the above study as compared to the larger sample $(n=220)$ in the present study. Although all participants in another study ${ }^{2}$ were symptomatic, the prevalence was relatively lower compared to the symptomatic participants in our study. The numbers of symptomatic patients in both studies were almost the same however the severity of the symptoms were not specified in that study. ${ }^{2}$

Consistent with our study, convergence insufficiency was also the most prevalent vergence disorder in various studies. ${ }^{2,18,21,22,23}$ However in contrast to our study, another study ${ }^{24}$ determined a greater prevalence of near esophoria than convergence insufficiency and in yet another, ${ }^{22}$ divergence insufficiency was the second prevalent vergence disorder. These differences may be attributed to the difference in study design, population and location. In the present study, individuals within only the teenage years were examined while one ${ }^{22}$ study above studied a wider age range of 8 to 49 years old. As a result of the commonalities of convergence insufficiencies among populations, several works have been done on them compared to the other vergence disorders ${ }^{25}$; again because of the many different works, specific questionnaires ${ }^{26,27,28,29}$ have been developed to investigate specifically these conditions. In contrast to the present study, two studies ${ }^{2,19}$ found convergence excess to be the most prevalent vergence disorder even though all these studies used similar diagnostic signs. Differences in 
study methodology and populations may have accounted for these discrepancies.

It is however difficult to compare the results of Metsing and Ferreira $^{8}$ with our study even though both studies were conducted among school-aged African populations. The present study considered and investigated specific vergence disorders, while the other study ${ }^{8}$ reported on prevalence of diagnostic signs like abnormal vergence amplitude and vergence facility. Some of the studies reviewed ${ }^{2,18}$ did not investigate for fusional vergence dysfunctions as one of the vergence disorders. This disorder of vergence was investigated for in this present study because some participants had no significant phorias at distance or near but had reduced fusional vergence ranges in both base-in and base-out directions. These clinical signs were described by Wick as fusional vergence dysfunction and are seen as a limitation in the classification by Duane according to one author. ${ }^{5}$ Comparable with our study, some related studies ${ }^{19,20}$ found lower prevalence of fusional vergence dysfunctions ranging from $1.5 \%$ to $1.8 \%$ among different populations. Rao, ${ }^{22}$ however, determined slightly higher prevalence of fusional vergence dysfunctions in a different population compared to the present study.

The asthenopic symptoms were all highly frequent among participants diagnosed with convergence insufficiency (Figure 3) in the present study; this was consistent with studies by Garcia-Munoz et al. ${ }^{25}$ and Westman et al. ${ }^{30}$ The result may be because of the commonalities of convergence insufficiencies among populations. ${ }^{25}$ In the Westman et al. ${ }^{30}$ study, participants diagnosed with convergence insufficiency frequently complained of blurred vision, difficulties when reading, tired eyes, diplopia, difficulties while doing close-up work, painful eyes, watery eyes and headaches. It is however difficult to compare specific prevalence figures of asthenopic symptoms among participants with convergence insufficiency because of differences in study population and design. Also, not all the symptoms in the aforementioned study ${ }^{30}$ were specified for near and far as was done in the present study.

There is a debate as to whether asthenopic symptoms are specific or non-specific to causative conditions. ${ }^{31}$ Investigating this, this study found statistically significant association between SVDs and some specific asthenopic symptoms. In contrast to this study, one pilot study ${ }^{21}$ among black JHS students found no significant association between the vergence disorders and asthenopic symptoms. In the pilot study, however, binocular assessment was performed over bestcorrected refractive prescriptions in contrast to the present study which used participant's habitual spectacle prescription if any or no correction. The other studies reviewed ${ }^{2,19,25,30} \mathrm{did}$ not report on any statistically significant associations between vergence disorders and asthenopic symptoms.

In conclusion, even though this study revealed significant associations between SVDs and some specific asthenopic symptoms in the participants' habitual state, it cannot be concluded that those asthenopic symptoms are specific to the vergence disorders diagnosed. This is so because most of these symptoms presented in other specific vergence disorders. This study thus concurs with the results of two studies $^{18,25}$ that presenting complaints of specific asthenopic symptoms does not clearly discriminate between the specific types of vergence disorders. It is recommended that further investigation be conducted among JHS participants in Ghana to compare the prevalence of vergence disorders in their bestcorrected refractive states and with reference also to participants who are asymptomatic.

\section{Acknowledgements}

We wish to acknowledge Ms. Carrin Martin, English editor for the School of Health Sciences, University of KwaZuluNatal.

\section{Competing interests}

The authors declare that they have no financial or personal relationships which may have inappropriately influenced them in writing this article.

\section{Authors' contributions}

C.D-T. conceived the project, designed the study, acquired data, analysed and interpreted data, drafted the article, revised it for important intellectual content and approved final copy for publication. N.E.K. was the project supervisor, revised article for important intellectual content and approved the article for publication. U.N. was a co-supervisor of this project, revised this article for important intellectual content and approved this article for publication.

\section{References}

1. Scheiman M, Gallaway M, Coulter R, et al. Prevalence of vision and ocular disease conditions in a clinical pediatric population. J Am Optom Assoc. 1996;67(4):193-202.

2. Lara F, Cacho P, García A, Megías R. General binocular disorders: Prevalence in a clinic population. Ophthal Physiol Opt. 2001; 21(1):70-74. http://dx.doi. org/10.1046/j.1475-1313.2001.00540.x

3. Maino DM. The binocular vision dysfunction pandemic. J Optom Vis Dev. 2010;41(1):6-13.

4. American Optometric Association. Care of the patient with Accommodative and Vergence Dysfunction. [serial online]. 2010 [cited 2013 Feb 09]; [7-9, 27-40]. Available from: http://www.aoa.org/documents/CPG-18.pdf

5. Scheiman M, Wick B. Clinical management of Binocular vision: Heterophoric accommodative, and eye movement disorders. Baltimore, MD: Lippincott Williams \& Wilkins; 2008.

6. Rouse $M$, Borsting $E$, Mitchell $G L$, et al. Academic behaviours in children with convergence insufficiency with and without parent-reported ADHD. Optom Vis Sci. 2009;86(10):1169-1177. http://dx.doi.org/10.1097/OPX.0b013e3181baad13

7. Cooper JS, Burns CR, Cotter S, Daum KM, Griffin JR, Scheiman MM. Accommodative and Vergence Dysfunction Prevention [serial online]. 2010 [cited 2014 Jun 18]; [107]. Available from: http://www.aoa.org/documents/CPG-18.pdf

8. Metsing I, Ferreira J. Accommodation and vergence status among the 3rd and 4 th graders in a mainstream school in Gauteng. S Afr Optom. 2012;71(1):22-31.

9. American Optometric Association. Optometric clinical practice guideline. [serial online]. 2002 [cited 2014 Jun 23]. Available from: http://opto.ca

10. Von Noorden GK, Campos EC. Binocular vision and ocular motility: Theory and management of strabismus. 6th ed. St. Louis, MO: Mosby Inc.; 2002.

11. Ovenseri-Ogbomo GO, Ocansey S, Abu EK, Kyei S, Boadi-Kusi SB. Oculo-visual findings among industrial mine workers at Goldfields Ghana Limited, Tarkwa. Ophthalmol Eye Dis. 2012;4:35-42.

12. Ovenseri-Ogbomo GO, Abraham $\mathrm{CH}$, Kio FE. Visual impairment and ocular findings among deaf and hearing impaired school children in Central Region, Ghana. J Med Biomed Sci. 2013;2(2):16-22. 
13. Opoku-Baah C, Mohammed AK, Afari C, et al. The management of binocular vision anomalies by eye care facilities in the Accra and Kumasi Metropolises (Ghana). Int J Innovat Appl Stud. 2014;9(3):1401-1408.

14. Metro Education Directorate. Data on 2011-2012 enrolment for public Junior High Schools. Cape Coast: Ghana Education Service; 2013

15. Bhanderi DJ, Choudhary S, Doshi VG. A community-based study of asthenopia in computer operators. Indian J Ophthalmol. 2008;56(1):51-55. http://dx.doi. org/10.4103/0301-4738.37596

16. Scheiman M, Gallaway M, Frantz KA, et al. Near point of convergence: Test procedure, target selection, and normative data. Optom Vis Sci. 2003;80:214225. http://dx.doi.org/10.1097/00006324-200303000-00011

17. Richman JE, Laudon RC. A survey of the prevalence of binocular and accommodative dysfunctions in a sample of optometry students. J Behav Optom. 2002;13(2):31-33.

18. Dwyer $P$. The prevalence of vergence accommodation disorders in a school-age population. Clin Exp Optom. 1991;75(1):10-18.

19. Porcar E, Martinez-Palomera A. Prevalence of general binocular dysfunctions in a population of university students. Optom Vis Sci. 1997;74(2):111-113. http:// dx.doi.org/10.1097/00006324-199702000-00023

20. Monte's-Mico R. Prevalence of general dysfunctions in binocular vision. Ann Ophthalmol. 2001;33(3):205-208. http://dx.doi.org/10.1007/s12009-001-0027-8

21. Wajuihian SO, Hansraj R. Near vision anomalies in black high school children in Empangeni, South Africa. S Afr Optom. 2014;73(1):21-32.

22. Rao D. Prevalence of non strabismic binocular vision disorders in patients with asthenopia. J Multidiscipl Res Healthc. 2014;1(1):33-41. http://dx.doi. org/10.15415/jmrh.2014.11003
23. Daum KM. Accommodative dysfunctions. Doc Opthalmol. 1983;5:177-198. http://dx.doi.org/10.1007/BF00140808

24. Hokoda SC. General binocular dysfunctions in an urban optometry clinic. J Am Optom Assoc. 1985;56:560-562.

25. Garcia-Munoz A, Carbonell-Bonete S, Cacho-Martinez P. Symptomatology associated with accommodative and binocular vision anomalies. J Optom. 2014;7(4):178-192. http://dx.doi.org/10.1016/j.optom.2014.06.005

26. Borsting EJ, Rouse MW, Mitchell GL, et al. Validity and reliability of the revised convergence insufficiency symptom survey in children aged 9-18 years. Optom Vis Sci. 2003;80(12):832-838. http://dx.doi.org/10.1097/00006324-20031200000014

27. Borsting $\mathrm{E}$, Rouse MW, De Land PN, Convergence Insufficiency and Reading Study (CIRS) Group. Prospective comparison of convergence insufficiency and normal binocular children on CIRS symptom surveys. Optom Vis Sci. 1999;76(4):221-228.

28. Conlon E, Lovegrove W, Chekaluk E, Pattison EP. Measuring visual discomfort. Vis Cognit. 1999;6(6):637-663. http://dx.doi.org/10.1080/135062899394885

29. Russell GE, Wick B. A prospective study of treatment of accommodative insufficiency. Optom Vis Sci. 1993;70(2):131-135. http://dx.doi.org/10.1097/00006324-19930200000009

30. Westman M, Liinamaa MJ. Relief of asthenopic symptoms with orthoptic exercises in convergence insufficiency is achieved in both adults and children. J Optom. 2014;5(2):62-67.

31. Sheedy JE, Hayes J, Engle J. Is all asthenopia the same? Optom Vis Sci. 2003;80(11):732-739. http://dx.doi.org/10.1097/00006324-20031100000008 